\title{
Glycemic and Insulinemic Responses of Vegetables and Beans Powders Supplemented Chapattis in Healthy Humans: A Randomized, Crossover Trial
}

\author{
Saeed Akhtar, ${ }^{1}$ Anam Layla, ${ }^{1}$ Piero Sestili $\mathbb{D}^{2},{ }^{2}$ Tariq Ismail ${ }^{D},{ }^{1}$ Khurram Afzal, ${ }^{1}$ \\ Albert A. Rizvanov, ${ }^{3}$ and Muhammad Hassham Hassan Bin Asad (i) ${ }^{3,4}$ \\ ${ }^{1}$ Institute of Food Science \& Nutrition, Bahauddin Zakariya University, Multan, Pakistan \\ ${ }^{2}$ Department of Biomolecular Sciences, Sports Science and Health Department, University of Urbino "Carlo Bo" Via "The Maggetti", \\ 2661029 Urbino, PU, Italy \\ ${ }^{3}$ Institute of Fundamental Medicine and Biology, Department of Genetics, Kazan Federal University, Kazan, Russia \\ ${ }^{4}$ Department of Pharmacy, COMSATS University Islamabad, Abbottabad Campus, 22060, Islamabad, Pakistan
}

\begin{abstract}
Correspondence should be addressed to Tariq Ismail; ammarbintariq@yahoo.com and Muhammad Hassham Hassan Bin Asad;
\end{abstract} hasshamasad@yahoo.com

Received 29 April 2019; Revised 2 July 2019; Accepted 16 August 2019; Published 13 October 2019

Academic Editor: Fabrizio Montecucco

Copyright (C) 2019 Saeed Akhtar et al. This is an open access article distributed under the Creative Commons Attribution License, which permits unrestricted use, distribution, and reproduction in any medium, provided the original work is properly cited.

\begin{abstract}
Vegetables and beans are nutrient-dense foods with innate potential to mediate diabetes in a variety of cultures. The present study aims at evaluating vegetables and beans for assessing their glycemic index and response in raising glucose levels in human model. Powdered formulations of vegetables and beans were designed to modulate glycemic response of carbohydrate-rich staples. A randomized, crossover trial was conducted in healthy young adults $(n=24)$ who were challenged with vegetable powder-supplemented chapatti (VPSC), bean powder-supplemented chapatti (BPSC) and all-purpose wheat flour chapatti (APFC) to evaluate their postprandial glucose (PPG) and postprandial insulin (PPI) responses. In comparison with APFC, feeding VPSC and BPSC to healthy volunteers anticipated significant reduction in PPG (44\% reduction in incremental area under the curve (AUC) for VPSC and 46\% reduction in incremental AUC for BPSC, $p=0.005)$. Likewise, significant reduction in PPI levels was observed for VPSC $(59 \%, p=0.012)$ and BPSC $(47 \%, p=0.002)$ compared to APFC-treated group. The study concludes wheat flour enrichment with vegetables and beans powder as a viable approach to develop cost effective and culturally acceptable low glycemic foods bearing acceptable sensory attributes.
\end{abstract}

\section{Introduction}

Diabetes is widely pervasive with 415 million diagnosed and 193 million undiagnosed cases. Moreover, about $12 \%$ share of global health expenditure is spent on the treatment of diabetes [1]. Asia has emerged as a major epicenter of diabetes epidemic, and the menace persistently prevails in most populous and middle-income countries of the region [2]. Poor control of diabetes evidently engenders risk of macrovascular and microvascular complications, resulting in the genesis of huge stress on the health-care system and socioeconomic status of the patients and caregivers. Reportedly, practicing a healthy dietary pattern with lifestyle modifications has come out as a potential strategy to avert diabetes [3].
Dietary habits that continually expose to post-meal hyperglycemia are believed to impair first-phase insulin secretion and decrease insulin sensitivity that might contribute an increased risk for insulin resistance and type 2 diabetes development [4]. Low glycemic index (GI) diets reduce postprandial glucose (PPG) by slowing digestion and the rate of nutrient influx from the gut and help to modulate insulin responses, thereby eliciting a beneficial effect in type 2 diabetes and other chronic maladies $[5,6]$. Relatively increased consumption of carbohydrate-rich foods generally leads to heightened daily glycemic load, thus annunciating them as candidates of interest for reducing PPG and postprandial insulin (PPI) responses [7]. Wheat and rice are the most common carbohydrate-rich staples in the indigenous food 
system of South Asia and are equally popular amongst Asian immigrant communities worldwide [8]. Glycemic indices of cereal based formulations like wheat and millet had been reported relatively lower than white rice recipes [9]. However, manipulation in comparatively high GI white rice recipes is practiced by replacing one serving with that of a low GI cereal to suppress PPG load [10].

Chickpea and red kidney beans are the low GI foods that hold substantial amounts of soluble fibers like galactomannan and resistance starch [11]. Delayed gastric emptying is referred as one amongst the possible mechanisms for improved metabolic control in diabetic patients [12]. Dietary fibers including those derived from beans increase the response of cholecystokinin - a hormone responsible for delayed gastric emptying and provoking satiety for food [13, 14]. Moreover, earlier researches also advocate fiber-anticipated viscosity and anti-nutrient-linked reduction in the rate of food digestion as possible reasons for delayed gastric emptying $[15,16]$.

Consumption of vegetables has been shown to evoke positive effect amongst diabetics by improving PPG excursions and insulin sensitivity [17]. Roots of turnip and radish are good sources of soluble fibers and minerals, especially magnesium and zinc, which are necessary cofactors for enzymes that improve glucose metabolism and insulin signaling pathways. Leafy vegetables such as mustard and cabbage have been explored for hypoglycemic and insulin sensitizing potential and suggested as adjuvants to oral hypoglycemic drugs $[18,19]$. Likewise, trace amounts of added cumin seeds (Nigella sativa L.) as part of its essential oil are physiologically meaningful in suppressing PPG [20]. These excelling features of beans and vegetables are of tremendous interest for researchers and health professionals to design low glycemic response cereal-based food products. The research in question was conducted to develop vegetable powder-enriched and beans powder-enriched wheat flour premixes for preparing organoleptically acceptable chapattis, and to evaluate PPG and PPI responses of the modified recipes in healthy human subjects.

\section{Materials and Methods}

2.1. Raw Materials. Commercially milled wheat flour, black cumin, red kidney beans, and chickpeas were sourced in one lot from the local supermarket of District Multan, Pakistan. Vegetables such as mustard, cabbage, turnip, and radish were procured from agro farm fields of city vicinity during their peak seasons. Analytical grade chemicals and reagents were used to perform biochemical analysis of the powdered vegetables and beans were procured from Merck (Darmstadt, Germany) and Sigma Chemical Co., Ltd. (St. Louise, MO) unless otherwise mentioned.

2.2. Production of Various Types of Composite Flour. Four different types of flour blends were prepared to elucidate the best organoleptic response using composite flour technology. All-purpose wheat flour being the base material was replaced at different proportions with bean and vegetable powder (VP) (Table 1).
TABLE 1: Ingredient-based composition of treatment models.

\begin{tabular}{lccccc}
\hline Ingredient $(\mathrm{g})$ & $T_{0}$ & $T_{1}$ & $T_{2}$ & $T_{3}$ & $T_{4}$ \\
\hline Wheat flour & 100 & 80 & 70 & 49.5 & 74.5 \\
Mustard powder & 0 & 3 & 6 & 0 & 0 \\
Cabbage powder & 0 & 7 & 10 & 0 & 0 \\
Turnip powder & 0 & 5 & 7 & 0 & 0 \\
Radish powder & 0 & 5 & 7 & 0 & 0 \\
Kidney beans flour & 0 & 0 & 0 & 20 & 10 \\
Gram flour & 0 & 0 & 0 & 30 & 15 \\
Powdered black cumin & 0 & 0 & 0 & 0.5 & 0.5 \\
\hline
\end{tabular}

$T_{0}=$ Control; $T_{1}$ and $T_{2}=$ Vegetable powder-supplemented treatments; $T_{3}$ and $T_{4}=$ Bean powder-supplemented treatments. $*$ Glycemic response assessment was performed only for the treatments with the best organoleptic responses.

2.3. Preparation of Chapattis. The newly developed flour blends along with control flour were used to make chapattis. Flour mixes were kneaded till soft consistency by the addition of water. Finally, the dough was developed and allowed for proofing duration of 30 minutes. The dough balls were rolled out with wooden rolling pin, and dough sheets measuring $18 \mathrm{~cm}$ were developed. Flatbreads having thickness of $3 \mathrm{~mm}$ each were baked on a hotplate at $210^{\circ} \mathrm{C}$ for $150 \mathrm{~s}$ [21].

2.4. Organoleptic Evaluation. Chapattis were organoleptically evaluated to select the best combination on the basis of appearance, color, taste, texture, folding ability, and acceptability on 9-point hedonic scale [21,22]. Organoleptically acceptable best quality baked chapattis made of composite flours were further used for glycemic response assessment. Sensory properties of the product were carried out by sensory experts' panel from the Institute of Food Science \& Nutrition, Bahauddin Zakariya University, Multan, Pakistan, with good product discriminative ability for different sensory attributes. The product was served to the experts under white light in the absence of food/chemical odor and unnecessary sound in the sensory analysis laboratory. Distilled water and crackers were used to clean the mouth between samples analysis. The panelists were provided with questionnaires to record their observations on 9-point hedonic scale.

2.5. Nutritional Profiling. Nutritional composition, including protein (920.87), fiber (920.86) and lipids (923.05) contents of chapattis with the best organoleptic response, was assessed by the methods laid down in AOAC manual of food analysis by Latimer [23].

2.6. Determination of Available Carbohydrates. Available carbohydrate contents of chapattis (dry weight basis) were measured by following phenol-sulphuric acid method [24]. One hundred milligrams of a homogeneous sample of dried chapattis powder was hydrolyzed in boiling water with $5 \mathrm{ml}$ $2.5 \mathrm{~N} \mathrm{HCl}$ for $3 \mathrm{hr}$ and neutralization was performed with sodium carbonate crystals. Boiling tubes carrying samples were cooled to $25^{\circ} \mathrm{C}$. Samples were centrifuged, and $5 \mathrm{ml}$ of $\mathrm{H}_{2} \mathrm{SO}_{4}$ was rapidly added in supernatant $(2 \mathrm{ml})$; subsequently, $1 \mathrm{ml}$ of $5 \%$ aqueous phenol was added to tube contents. The samples were vortexed (30s) and kept at room temperature 
for $20 \mathrm{~min}$. The intensity of color resulting so was measured against blank at $490 \mathrm{~nm}$ using a spectrophotometer (UV-Vis 3000, ORI, Germany). All chapatti samples were tested in three replicates and carbohydrate concentrations were determined using glucose standard solutions of known concentration.

\subsection{Glycemic Indexing and Insulin Response Assessment of BPSC and VPSC Chapattis}

2.7.1. Participants of the Study. Normoglycemic healthy young adults were recruited from staff/students of Bahauddin Zakariya University, Multan, Pakistan. The study was approved by a bioethics committee of Bahauddin Zakariya University, Multan, Pakistan (Reg. No. 04-18/2018), and was executed taking into consideration the ethical principles mentioned in the Declaration of Helsinki. Eligible participants were normoglycemic healthy individuals entailing age limit (1830 years), body mass index $\left(18.5-24.9 \mathrm{~kg} / \mathrm{m}^{2}\right)$ and fasting glucose levels $(<6 \mathrm{mmol} / \mathrm{L})$. The exclusion criteria were built on smoking, excessive alcohol consumption ( $>50 \mathrm{~g} /$ day), body weight change $>5 \%$ in the past six months, pregnancy or lactation, any type of chronic metabolic disease, regular use of supplements/medications, for example, birth control pills, anti-asthmatic, diuretics that might interfere with glucose and lipid metabolism, or those unwilling to follow the study protocol. Of total twenty-seven screened, selected subjects, three refused to participate due to unavailability to attend all test sessions. Finally, twenty-four enrolled subjects provided written informed consent and completed the study. Participants were physically examined, and base line demographic data were assessed before GI testing.

2.7.2. Reference Food/Test Meal. The reference beverage was prepared by dissolving $55 \mathrm{~g}$ dextrose monohydrate (Glaxose-D glucose powder, Unilever Pakistan Food Ltd., Karachi, Pakistan) in $250 \mathrm{ml}$ water and was dispensed to the subjects during test sessions.

Selected BPSC and VPSC were freshly prepared at serving time in the metabolic kitchen of the research center and were served with fried egg (54g wt., $15.4 \%$ lipids, $13.3 \%$ protein, $0.6 \%$ carbohydrates) cooked in sunflower oil. Meal palatability was increased by serving $250 \mathrm{ml}$ water to the participants along with the meal. Available carbohydrate contents were used to calculate portion size of the test foods.

2.7.3. Experimental Protocol. Subjects were challenged with three experimental diets, that is, (1) APFC (control), (2) BPSC, and (3) VPSC in random order on non-consecutive week days. Assessment was conducted in four non-consecutive week days over a period of 6-8 weeks during July 2018-August 2018 , and an interval of two weeks was set between visits. The proportions of each diet were standardized to yield $50 \mathrm{~g}$ available carbohydrate content. Glucose beverage equivalent to deliver $50 \mathrm{~g}$ available carbohydrates was used as a standard for GI determination. The experimental procedure used to measure GI was adopted by $\mathrm{FAO} / \mathrm{WHO}$ recommended method [25]. The study subjects were individually informed to avoid vigorous physical activity and smoking. Brief behavioral questionnaire and 24-hour recall were used to ensure balanced evening meal consumption by the participants. Subjects were asked to visit research center early morning with $\sim 12 \mathrm{hr}$ fasting, but were allowed to drink water ad lib during overnight fast. Fasted subjects were provided with standard glucose beverage or freshly prepared chapattis. All subjects were advised to finish their test meals within $15 \mathrm{~min}$. Blood sampling was performed during 2 hours post-test meal consumption for PPG and PPI analysis.

2.7.4. Blood Glucose and Insulin Measurements. Capillary blood sampling was performed in the fasted subjects at -5 and 0 min (two baseline measurements). Postprandial blood sampling was performed at 15, 30, 45, 60, 90 and $120 \mathrm{~min}$ from the baseline sampling. Blood glucose concentrations were assessed using a lancet device manufactured by Accu-Chek Performa, Roche Diabetes Care $\mathrm{GmbH}$, Germany. The device was calibrated every day prior to testing, using control solution and the blood chemistry analyzer (Biosystem BTS-350, Spain). Insulin response was assessed by drawing $2 \mathrm{ml}$ postprandial venous blood samples in serum separator vacutainers at 0, 30, 60 and $120 \mathrm{~min}$ for the estimation of insulin response. Blood samples were centrifuged for $5 \mathrm{~min}$ at $3000 \mathrm{rpm}$ and $25^{\circ} \mathrm{C}$. Serum samples were collected in the $1.5 \mathrm{ml}$ labelled Eppendorf tubes and stored in ultralow temperature freezer (MDF-U33V-PB, Japan) at $-70^{\circ} \mathrm{C}$. Serum insulin concentrations were measured on microtiter plate reader using the sandwich ELISA technique with immunoassay kit (Human insulin, Chemux BioScience, South San Francisco) with standard range of 5-200 U/mL.

2.8. Data Analysis. Physicochemical analysis data of products were statistically analyzed by analysis of variance (ANOVA) technique using computerized program Statistix 8.1 (Tallahassee, FL). Trapezium rule without using values below the baseline was used to perform time point differences analysis and incremental area under the curve (iAUC) calculations for blood glucose and insulin response assessment [25]. Differences amongst the means were determined by post-hoc analysis and confidence interval was set at 5\% $(p<0.05)$. Graphs were designed using GraphPad Prism 7.0 (CA, USA) [26].

\section{Results}

3.1. Organoleptic Evaluation of VPSC and BPSC. Data presented in Table 2 showed that the addition of VP antagonistically influenced color and appearance $(p<0.05)$ that render a typical out look to the product under sensory evaluation. The addition of VP (20\% \& 30\%) and BP (50\%) slightly deteriorated the texture characteristics of VPSC and BPSC nevertheless chapattis remained acceptable to judges. Supplementation of BP at $50 \%$ and $25 \%$ and VP at $20 \%$ in APF to make VPSC and BPSC did not negatively affect the taste of the finished product (Table 2).

3.2. Nutritional Profiling of VPSC and BPSC. Nutritional composition of VPSC and BPSC balanced out to deliver $50 \mathrm{~g}$ of available carbohydrates is stated in Table 3. Nonsignificant $(p<0.05)$ difference was observed in carbohydrate contents of VPSC and BPSC, but supplementation of APF with VP and BP evidently enhanced nutrient profile of chapattis when 
TABLE 2: Sensory evaluation of APFC, VPSC and BPSC prepared with different combinations.

\begin{tabular}{lcccccc}
\hline Product Type & Appearance & Color & Texture & Taste & Folding ability & Overall palatability \\
\hline$T_{0}$ & $7.80 \pm 0.27^{\mathrm{a}}$ & $7.30 \pm 0.24^{\mathrm{a}}$ & $7.50 \pm 0.19^{\mathrm{a}}$ & $7.20 \pm 0.3^{\mathrm{a}}$ & $7.58 \pm 0.19^{\mathrm{a}}$ & $7.49 \pm 0.27^{\mathrm{a}}$ \\
$T_{1}$ & $6.85 \pm 0.28^{\mathrm{bc}}$ & $6.63 \pm 0.24^{\mathrm{b}}$ & $6.53 \pm 0.19^{\mathrm{bc}}$ & $7.02 \pm 0.31^{\mathrm{a}}$ & $7.04 \pm 0.19^{\mathrm{ab}}$ & $6.86 \pm 0.28^{\mathrm{ab}}$ \\
$T_{2}$ & $6.19 \pm 0.33^{\mathrm{c}}$ & $6.50 \pm 0.28^{\mathrm{b}}$ & $5.84 \pm 0.28^{\mathrm{c}}$ & $5.47 \pm 0.37^{\mathrm{b}}$ & $6.64 \pm 0.25^{\mathrm{bc}}$ & $6.13 \pm 0.36^{\mathrm{c}}$ \\
$T_{3}$ & $7.00 \pm 0.23^{\mathrm{b}}$ & $7.36 \pm 0.18^{\mathrm{a}}$ & $6.17 \pm 0.35^{\mathrm{c}}$ & $6.56 \pm 0.31^{\mathrm{a}}$ & $6.15 \pm 0.34^{\mathrm{c}}$ & $6.69 \pm 0.26^{\mathrm{bc}}$ \\
$T_{4}$ & $7.30 \pm 0.19^{\mathrm{ab}}$ & $7.50 \pm 0.21^{\mathrm{a}}$ & $7.15 \pm 0.27^{\mathrm{ab}}$ & $7.26 \pm 0.24^{\mathrm{a}}$ & $7.23 \pm 0.26^{\mathrm{ab}}$ & $7.33 \pm 0.13^{\mathrm{ab}}$ \\
\hline
\end{tabular}

$T_{0}=100 \% \mathrm{PF}: T_{1}=80 \% \mathrm{PF}+20 \% \mathrm{VP}: T_{2}=70 \% \mathrm{PF}+30 \% \mathrm{VP}: T_{3}=50 \% \mathrm{PF}+50 \% \mathrm{BP}: T_{4}=75 \% \mathrm{PF}+25 \% \mathrm{BP} . *$ Means sharing similar lettering in a column is nonsignificantly different at $p \geq .05$, Mean \pm SD.

TABLE 3: Nutritional composition of APFC, VPSC and BPSC selected on the basis of sensory responses- $50 \mathrm{~g}$ ACB.

\begin{tabular}{lccc}
\hline Nutrients (per serving) & $T_{0}$ & $T_{1}$ & $T_{4}$ \\
\hline Energy (kJ) & 959.1 & 1015.3 & 1029.9 \\
Total fat (g) & 0.81 & 0.90 & 1.14 \\
Protein (g) & 5.05 & 8.62 & 8.92 \\
ACB (g) & 50 & 50 & 50 \\
TDF (g) & 3.60 & 6.72 & 5.33 \\
Serving size (g) & 91.2 & 96.10 & 93.4 \\
\hline
\end{tabular}

$\mathrm{ACB}=$ Available carbohydrates basis; $\mathrm{TDF}=$ total dietary fiber: $T_{0}=100 \%$ PF: $T_{1}=80 \%$ PF $+20 \%$ VP: $T_{4}=75 \%$ PF $+25 \%$ BP. Mean \pm SD.

compared with control. Likewise, the addition of BP (25\%) to APF exhibited slightly higher crude fat level in BPSC $(1.14 \mathrm{~g})$, while the addition of VP $(20 \%)$ failed to change $(p>0.05)$ total fat in VPSC, as compared to the chapattis made by APF only. Interestingly, the addition of cruciferous vegetable and bean powder, both being good sources of proteins, significantly $(p<0.05)$ improved protein contents of VPSC and BPSC by $41 \%$ and $43 \%$, respectively, when compared with APFC.

3.3. Glycemic Indexing and Glycemic Load Assessment. Baseline clinical and anthropometric characteristics of the subjects separated by sex have been presented in Table 4 . The mean fasting capillary glucose of subjects was $5.2 \mathrm{mmol} / \mathrm{L}$. Postprandial glucose responses of experimental foods using iAUC and their GI values are summarized in Table 5. In comparison with the APFC bearing highest GI, that is, 82 , lowest GI values were recorded for chapattis made of BPSC (44), and VPSC (46), that represented $46 \%$ and $44 \%$ decrease in GI values of BPSC and VPSC, respectively.

3.4. Postprandial Glycemic and Insulinemic Responses. The postprandial glycemic response curves comparing the high GI (APFC) and low GI (VPSC and BPSC) food products are illustrated in Figure 1. The low GI-chapattis flattered glycemic response and shifted the response curve downwards, as compared to APFC. Time point differences in postprandial blood glucose concentrations were statistically lower at $15 \mathrm{~min}$ $(p=0.022), 30 \mathrm{~min}(p=0.018)$ and $45 \mathrm{~min}(p=0.0018)$ for VPSC. Significant differences in the postprandial glucose concentration were also observed for BPSC treated group at $15 \min (p=0.017), 30 \min (p=0.012)$ and $45 \min (p=0.011)$. The postprandial glucose response to BPSC at $120 \mathrm{~min}$ tended towards lower side than APFC and VPSC. Significant reduction in $\mathrm{iAUC}_{0-120 \mathrm{~min}}$ values of blood glucose was observed for VPSC
TABLE 4: Gender-based demographic characteristics of the subjects administered APFC, VPSC and BPSC.

\begin{tabular}{lcc}
\hline $\begin{array}{l}\text { Subjects } \\
\text { characteristics }\end{array}$ & $\begin{array}{c}\text { Male }(n=12) \\
\text { Mean } \pm \text { SD }\end{array}$ & $\begin{array}{c}\text { Female }(n=12) \\
\text { Mean } \pm \text { SD }\end{array}$ \\
\hline Age (years) & $21.1 \pm 1.2$ & $23.8 \pm 2.6$ \\
Height $(\mathrm{m})$ & $1.7 \pm 0.04$ & $1.6 \pm 0.07$ \\
Weight $(\mathrm{kg})$ & $66.7 \pm 4.5$ & $56.3 \pm 7.7$ \\
BMI $\left(\mathrm{kg} / \mathrm{m}^{2}\right)$ & $22.5 \pm 1.7$ & $21.0 \pm 1.7$ \\
WC $(\mathrm{in})$ & $33.7 \pm 1.1$ & $32.3 \pm 1.3$ \\
FBG $(\mathrm{mmol} / \mathrm{l})$ & $5.3 \pm 0.3$ & $5.2 \pm 0.3$ \\
\hline
\end{tabular}

$\mathrm{WC}=$ waist circumference: $\mathrm{FBG}=$ fasting blood glucose; Mean $\pm \mathrm{SD}$.

TABLE 5: Incremental area under curve (iAUC) and glycemic index of tested vegetable powder and beans powder products.

\begin{tabular}{lccc}
\hline Group & Mean iAUC \pm SEM & GI \pm SEM & Glycemic ranking \\
\hline APFC & $150 \pm 16^{\mathrm{a}}$ & $82 \pm 16^{\mathrm{a}}$ & High \\
VPSC & $75 \pm 14^{\mathrm{b}}$ & $46 \pm 14^{\mathrm{b}}$ & Low \\
BPSC & $84 \pm 11^{\mathrm{b}}$ & $44 \pm 11^{\mathrm{b}}$ & Low \\
\hline
\end{tabular}

* Means sharing similar lettering in a column is nonsignificantly different at $p \geq .05$, Mean \pm SE.

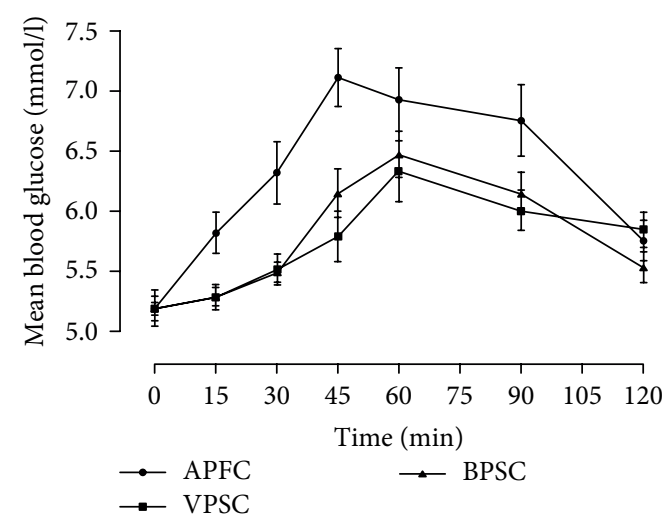

FIgURE 1: Glycemic response to low and high glycemic index (GI) chapattis.

(49\%) and BPSC (44\%) in comparison with the normal control $(p=0.005)$. Sixty minutes post ingestion of VPSC and BPSC also revealed significantly $(p=0.0003)$ lower values of insulin as compared to APFC (Figure 2). Amplitude of postprandial insulin responses was significantly shortened and lowered for VPSC ( $p=0.012)$ and BPSC ( $p=0.002)$ as compared to the APFC. 


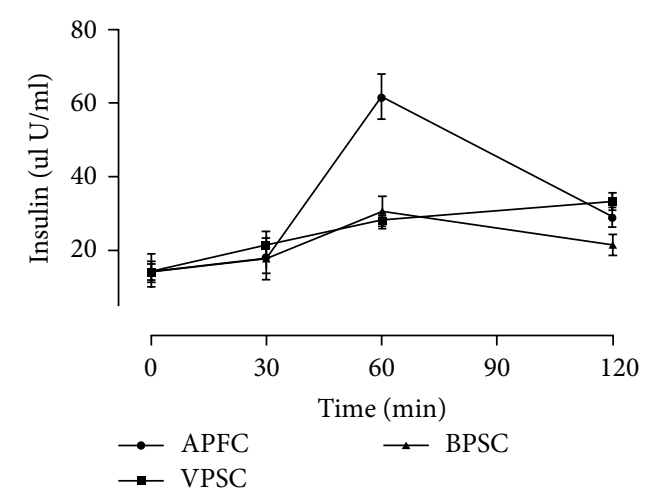

FIGURE 2: Insulin response to high- and low-glycemic index chapattis.

\section{Discussion}

The data presented above confirmed supplementing vegetable and bean powder to the refined carbohydrate staples may improve short-term glycemia and insulinemia; however, could not be generalized to the individuals with type 2 diabetes. Reduction in taste of VPSC at 30\% supplementation is predominately associated with mustard leaves and the study validates findings of Chin \& Lindsay [27] who reported isothiocyanates producing sulfurous aroma and pungent flavor from shredded and cooked brassica tissues. Results of the present study for various sensory traits of VPSC and BPSC were consistent with those of folding ability and overall palatability: the combination $T_{2}$ and $T_{3}$ ranked the lowest in the overall acceptability of the baked chapattis. This finding is consistent with the analogous observation that supplementing cereals with unconventional food crops beyond $25 \%$ reduces consumers' acceptability index $[28,29]$. Based on the above-mentioned sensorial observations, VPSC and BPSC prepared from the flour blends $T_{1}(80 \% \mathrm{APF}+20 \% \mathrm{VP})$ and $\mathrm{T}_{4}(75 \%$ $\mathrm{APF}+25 \% \mathrm{BP}$ ) were used in nutritional profiling of the products and their glycemic response assessment. Irrespective of matchable carbohydrate profile, higher protein and fat contents in VPSC and BPSC contributed 56-70 calories per serving higher than APFC. In comparison with control, that is, APFC, 3.6-3.9g higher protein and 1.7-3.1 g higher fiber contents per serving were observed in VPSC and BPSC that may contribute significant differences in glycemic and insulinemic performance. In analogy with our results (Table 3), better nutritional profiles were reported for composite baked -roll cakes produced from soybean and vegetable flour instead of wheat flour [30]. These findings further strengthened the notion that new formulations (VPSC \& BPSC) may deliver more calories from non-carbohydrate sources that might be beneficial for individuals with insulin resistance.

Supplementation of VP (20\%) and BP (25\%) in APF significantly $(p<0.0024)$ reduced mean iAUC of the tested products. The assigned GI values for newly developed recipes (VPSC and BPSC) non-significantly ( $p \geq 0.05)$ differed from each other suggesting both formulations to be equally beneficial in reducing postprandial blood glucose spikes. Several groups of investigators reported low $(\leq 55)$ to high $(\geq 70)$ GI scoring to wheat flour chapattis $[31,32]$ that could be associated with myriad of factors including varied fiber, starch and gluten contents, method of processing or cooking, presence of anti-nutrients, slowly digestible and resistant starch which were corollary to influence GI values [33]. Higher GI values, that is, $\geq 70$ have been reported for white flour bread, while whole wheat flour and fiber supplementation in white wheat flour have been cited with low GI values, that is, 54\% [34]. The results of this study are in agreement to the findings of Radhika et al. [31] and Gopalpura et al. [35] who reported wheat flour formulations mixed with legumes (Bengal grams flour) and soluble viscous fibers (psyllium and fenugreek powder) to demonstrate their potential in lowering GI values of chapattis. The outcomes of the current study point to the potential of VPSC and BPSC to lower GI. Hence, due to their lower glycemic response, both VPSC and BPSC might represent a valuable tool in diabetes management, more particularly in regions reported with consumption of high glycemic load-bearing staples.

Our study clearly shows that VP and BP mixes are viable formulations as compared to standard APFC to lower PPG and PPI responses in the context of the Asian population, where escalating prevalence of type 2 diabetes appears to be a serious threat and public health issue. Our findings are corroborated by the upshots of foregoing exploratory studies where combinations of bean powder and fiber mixes with wheat flour decreased PPG ( $\geq 30 \%$ reduction in $\left.\mathrm{iAUC}_{0-20 \mathrm{~min}}\right)$ and PPI ( $\geq 28 \%$ reduction in $\left.\mathrm{tAUC}_{0-120 \mathrm{~min}}\right)$ as compared to commercial wheat flour-based chapattis [36, 37]. Another study by Johnson et al. [38] reported 35\% chickpea flour incorporation to wheat flour significantly decreased glycemic response of the products. Contrarily to the use of mixed grains formulations in hyperglycemia management, single chickpea-based meal has also been reported to lower both the glucose and insulin amount (55\% reduction in PPG at 30 and 60 min while PPI at 120 min time point) [39].

The results of this study seem to be novel in that the developed formulations using VP and BP mixed with APF for making chapattis are significantly effective in reducing PPG and PPI levels. The present findings on PPG and PPI responses for VP mix chapatti served with fried egg could not be compared with earlier studies wherein vegetable curries served with wheat flour chapattis significantly reduced PPG and PPI [40, 41]. We developed and focused on combinations of various vegetables and beans in the form of powder mixed with wheat flour, while retrospective studies focused on vegetables dispensed as curries. Likewise, Imai et al. [17] suggested the inclusion of vegetables before eating carbohydrates meal considerably reduce glucose excursions and PPG responses $(\geq 39 \%$ reduction in $\mathrm{iAUC}_{0-3 \text { hour }}$ ) in type 2 diabetes patients. The therapeutic effects of vegetables on lowering PPG and PPI levels are probably due to high fibers and lente carbohydrates which exhibit viscous and gel-forming properties. Such a composition may lead to delayed rate of gastric emptying and nutrients absorption and finally result in lower PPG response that requires less insulin for subsequent metabolic disposal [19, 42]. To this regard, it may be presumed that fibers and bioactive compounds from vegetable powder through the modification of gastric conditions for hydrolytic enzymes activity result in slower release of nutrients thereby lowering PPG and PPI responses. Furthermore, cruciferous vegetables-largely 
included in our $\mathrm{VP}$ - are a uniquely rich source of isothiocyanates that are known to help in blood glucose control and beneficially influence insulin sensitivity [43].

The ability of chickpeas and red kidney beans to mitigate high glycemic response has been reported in many studies where the impact of dried beans on PPG and PPI was investigated in both healthy and type 2 diabetes subjects consuming high glycemic carbohydrates [44-46]. The postprandial glucose lowering potential of red kidney beans was attributed to viscous soluble fibers-mainly galactomannan and amylose rich starch granules-which might have stayed intact during simulated digestion [46]. Likewise, chickpea flour delivers highest amount of slow release starches amongst pulses that reduce post meal gastric emptying rate and glucose absorption to modulate PPG and PPI responses [47].

Findings of this recent study and literature as discussed above confirmed that partial replacement of wheat flour with dehydrated beans and vegetables is a likely approach for lowering PPG and PPI responses due to their higher contents of fiber as compared to the counterpart. Future research may identify the role of resistant and slow release starches from beans and vegetables powder to influence PPG and PPI responses in supplemented foods like chapattis. The study suggests explorative research to evaluate metabolic effects of vegetables and beans powder mix consumption in peoples with type 2 diabetes, and to investigate ghrelin, incretin and glucagon responses towards these kinds of flour formulations to better understand overall nature of their physiological responses.

\section{Data Availability}

The data used to support the findings of this study are available from the corresponding upon request.

\section{Conflicts of Interest}

The authors declare that they have no conflicts of interest.

\section{Acknowledgments}

The present work was a part of M. Phil thesis of a research scholar Anam Layla, supervised by Dr. Saeed Akhtar. The authors acknowledge Dr. Alexandra L. Jenkins, Clinical Nutrition and Risk Factor Modification Centre, St Michael's Hospital Toronto, Canada, for her technical assistance and valuable suggestions in executing this study.

\section{References}

[1] K. Ogurtsova, J. D. da Rocha Fernandes, Y. Huang et al., "IDF Diabetes Atlas: global estimates for the prevalence of diabetes for 2015 and 2040," Diabetes Research and Clinical Practice, vol. 128 , pp. 40-50, 2017.

[2] NCD Risk Factor Collaboration, "Worldwide trends in diabetes since 1980: a pooled analysis of 751 population-based studies with 4.4 million participants," Lancet, vol. 387, no. 10027, pp. 1513-1530, 2016.
[3] W. C. Knowler, E. Barrett-Connor, S. E. Fowler et al., "Reduction in the incidence of type 2 diabetes with lifestyle intervention or metformin," The New England Journal of Medicine, vol. 346, no. 6, pp. 393-403, 2002.

[4] A. Ceriello and S. Colagiuri, "International diabetes federation guideline for management of postmeal glucose: a review of recommendations," Diabetic Medicine, vol. 25, no. 10, pp. 1151-1156, 2008.

[5] J. Bolsinger, M. Landstrom, A. Pronczuk, A. Auerbach, and K. C. Hayes, "Low glycemic load diets protect against metabolic syndrome and type 2 diabetes mellitus in the male Nile rat," The Journal of Nutritional Biochemistry, vol. 42, pp. 134-148, 2017.

[6] D. J. Jenkins, C. W. Kendall, L. S. Augustin et al., "Effect of legumes as part of a low glycemic index diet on glycemic control and cardiovascular risk factors in type 2 diabetes mellitus: a randomized controlled trial," Archives of Internal Medicine, vol. 172, no. 21, pp. 1653-1660, 2012.

[7] D. Lafiandra, G. Riccardi, and P. R. Shewry, "Improving cereal grain carbohydrates for diet and health," Journal of Cereal Science, vol. 59, no. 3, pp. 312-326, 2014.

[8] P. Thomas, An exploration of Dietary Practices among South Indians in Brisbane, The University of Queensland Australia, Australia, 2016, Dissertation.

[9] S. Shobana, S. R. Kumari, N. G. Malleshi, and S. Z. Ali, "Glycemic response of rice, wheat and finger millet based diabetic food formulations in normoglycemic subjects," International Journal of Food Sciences and Nutrition, vol. 58, no. 5, pp. 363-372, 2007.

[10] M. Sakuma, H. Yamanaka-Okumura, Y. Naniwa et al., "Dosedependent effects of barley cooked with white rice on postprandial glucose and Desacyl Ghrelin levels," Journal of Clinical Biochemistry and Nutrition, vol. 44, no. 2, pp. 151-159, 2009.

[11] A. García-Alonso, I. Goni, and F. Saura-Calixto, "Resistant starch and potential glycaemic index of raw and cooked legumes (lentils, chickpeas and beans)," Zeitschrift für Lebensmitteluntersuchung und-Forschung A, vol. 206, no. 4, pp. 284-287, 1998.

[12] T. K. Ray, K. M. Mansell, L. C. Knight, L. S. Malmud, O. E. Owen, and G. Boden, "Long-term effects of dietary fiber on glucose tolerance and gastric emptying in noninsulindependent diabetic patients," The American Journal of Clinical Nutrition, vol. 37, no. 3, pp. 376-381, 1983.

[13] T. H. Moran and P. R. McHugh, "Cholecystokinin suppresses food intake by inhibiting gastric emptying," American Journal of Physiology-Regulatory, Integrative and Comparative Physiology, vol. 242, no. 5, pp. R491-R497, 1982.

[14] I. Bourdon, B. Olson, R. Backus, B. D. Richter, P. A. Davis, and B. O. Schneeman, "Beans, as a source of dietary fiber, increase cholecystokinin and apolipoprotein $\mathrm{b} 48$ response to test meals in men," The Journal of Nutrition, vol. 131, no. 5, pp. 1485-1490, 2001.

[15] M. J. Thorne, L. U. Thompson, and D. J. Jenkins, "Factors affecting starch digestibility and the glycemic response with special reference to legumes," The American Journal of Clinical Nutrition, vol. 38, no. 3, pp. 481-488, 1983.

[16] X. Xu, D. Brining, A. Rafiq, J. Hayes, and J. Chen, "Effects of enhanced viscosity on canine gastric and intestinal motility," Journal of Gastroenterology and Hepatology, vol. 20, no. 3, pp. 387-394, 2005.

[17] S. Imai, M. Fukui, N. Ozasa et al., "Eating vegetables before carbohydrates improves postprandial glucose excursions," Diabetic Medicine, vol. 30, no. 3, pp. 370-372, 2013. 
[18] S. Manchali, K. N. C. Murthy, and B. S. Patil, "Crucial facts about health benefits of popular cruciferous vegetables," Journal of Functional Foods, vol. 4, no. 1, pp. 94-106, 2012.

[19] K. Platel and K. Srinivasan, "Plant foods in the management of diabetes mellitus: vegetables as potential hypoglycemic agents," Molecular Nutrition and Food Research, vol. 41, no. 2, pp. 68-74, 1997.

[20] R. Mohtashami, M. Amini, H. Fallah Huseini et al., "Blood glucose lowering effects of Nigella sativa L. seeds oil in healthy volunteers: a randomized, double-blind, placebo-controlled clinical trial," Journal of Medicinal plants, vol. 3, no. 39, pp. 90-94, 2011.

[21] S. Akhtar, F. M. Anjum, S.-U. Rehman, Sheikh, M. A., and K. Farzana, "Effect of fortification on physico-chemical and microbiological stability of whole wheat flour," Food Chemistry, vol. 110, no. 1, pp. 113-119, 2008.

[22] D. G. Land and R. Shepherd, "Scaling and Ranking Methods," Sensory Analysis of Foods, Elsevier Applied Science, LondonJ. R. Piggott, Ed., pp. 155-185, 1988.

[23] G. W. Latimer, Official Methods of Analysis of AOAC International, AOAC International, Washington DC (USA), 19th edition, 2012.

[24] S. Krishnaveni, T. Balasubramanian, and S. Sadasivam, "Sugar distribution in sweet stalk sorghum," Food Chemistry, vol. 15, no. 3, pp. 229-232, 1984.

[25] FAO/WHO, "Carbohydrates in human nutrition: Report of joint FAO/WHO expert consultation," FAO Food and Nutrition Paper, vol. 66, pp. 1-140, 1998.

[26] R. G. D. Steel, J. H. Torrie, and D. Dickey, Principles and Procedures of Statistics: A Biometrical Approach, McGraw Hill Book Co. Inc, New York, 3rd edition, 1997.

[27] H. W. Chin and R. C. Lindsay, "Modulation of volatile sulfur compounds in cruciferous vegetables," ACS Symposium Series (USA), 1994.

[28] S. A. O. Adeyeye, A. O. Adebayo-Oyetoro, and S. A. Omoniyi, "Quality and sensory properties of maize flour cookies enriched with soy protein isolate," Cogent Food \& Agriculture, vol. 3, p. 1278827, 2017.

[29] K. Mezgebo, T. Belachew, and N. Satheesh, "Optimization of red teff flour, malted soybean flour, and papaya fruit powder blending ratios for better nutritional quality and sensory acceptability of porridge," Food Science \& Nutrition, vol. 6, pp. 891-903, 2018.

[30] N. Risk, "Formulating baked-roll cake by using a composite of wheat flour, soy flour, and vegetable flour (carrot, purple yam, and red bean) as a healthy snack for children aged 5-6 Years at Kindergarten in Tangerang," International Journal of Multidisciplinary and Current Research, vol. 5, pp. 1087-1093

[31] G. Radhika, C. Sumath, A. Ganesan, V. Sudha, C. Jeya Kumar Henry, and V. Mohan, "Glycemic index of Indian flatbreads (rotis) prepared using whole wheat flour and 'atta mix'-added whole wheat flour," British Journal of Nutrition, vol. 103, no. 11, pp. 1642-1647, 2010.

[32] K. I. Khawaja, A. Fatima, S. A. Mian et al., "Glycemic, insulin and ghrelin responses to traditional South Asian flatbreads in diabetic and healthy subjects," British Journal of Nutrition, vol. 108, no. 10, pp. 1810-1817, 2012.

[33] M. J. Thorne, L. U. Thompson, and D. J. Jenkins, "Factors affecting starch digestibility and the glycemic response with special reference to legumes," American Journal of Clinical Nutrition, vol. 38, no. 3, pp. 481-488, 1983.
[34] M. De Angelis, C. G. Rizzello, G. Alfonsi et al., "Use of sourdough lactobacilli and oat fibre to decrease the glycaemic index of white wheat bread," British Journal of Nutrition, vol. 98, no. 6, pp. 1196-1205, 2007.

[35] P. B. Gopalpura, C. Jayanthi, and S. Dubey, "Effect of Trigonella foenum-graecum seeds on the glycemic index of food: a clinical evaluation," International Journal of Diabetes Developing Countries, vol. 27, no. 2, pp. 41-45, 2007.

[36] H. M. Boers, K. MacAulay, P. Murray, R. Dobriyal, D. J. Mela, and M. A. M. Spreeuwenberg, "Efficacy of fibre additions to flatbread flour mixes for reducing post-meal glucose and insulin responses in healthy Indian subjects," British Journal of Nutrition, vol. 117, no. 3, pp. 386-394, 2017a.

[37] H. M. Boers, K. MacAulay, P. Murray et al., "Efficacy of different fibres and flour mixes in South-Asian flatbreads for reducing post-prandial glucose responses in healthy adults," European Journal of Nutrition, vol. 56, no. 6, pp. 2049-2060, $2017 \mathrm{~b}$.

[38] S. K. Johnson, S. J. Thomas, and R. S. Hall, "Palatability and glucose, insulin and satiety responses of chickpea flour and extruded chickpea flour bread eaten as part of a breakfast," European Journal of Clinical Nutrition, vol. 59, no. 2, pp. 169176, 2005.

[39] P. Nestel, M. Cehun, and A. Chronopoulos, "Effects of long-term consumption and single meals of chickpeas on plasma glucose, insulin, and triacylglycerol concentrations," American Journal of Clinical Nutrition, vol. 79, no. 3, pp. 390-395, 2004.

[40] M. Shoaib Akhtar, K. Almas, T. Kausar, and T. M. S. Wolever, "Blood glucose responses to traditional South Asian vegetable dishes in normal and diabetic human subjects," Nutrition Research, vol. 22, no. 9, pp. 989-996, 2002.

[41] F. William, S. Lakshminarayanan, and H. Chegu, "Effect of some Indian vegetables on the glucose and insulin response in diabetic subjects," International Journal of Forensic Sciences, vol. 44, no. 3, pp. 191-195, 1993.

[42] S. Imai, M. Fukui, and S. Kajiyama, "Effect of eating vegetables before carbohydrates on glucose excursions in patients with type 2 diabetes," Journal of Clinical Biochemistry and Nutrition, vol. 54, no. 1, pp. 7-11, 2014.

[43] X. Jia, L. Zhong, Y. Song, Y. Hu, G. Wang, and S. Sun, "Consumption of citrus and cruciferous vegetables with incident type 2 diabetes mellitus based on a meta-analysis of prospective study," Primary Care Diabetes, vol. 10, no. 4, pp. 272-280, 2016.

[44] A. M. Hutchins, D. M. Winham, and S. V. Thompson, "Phaseolus beans: impact on glycemic response and chronic disease risk in human subjects," British Journal of Nutrition, vol. 108, no. S1, pp. S52-S65, 2012.

[45] D. M. Winham, A. M. Hutchins, and S. V. Thompso, "Glycemic response to black beans and chickpeas as part of a rice meal: a randomized cross-over trial," Nutrients, vol. 9, no. 10, p. 1095, 2017.

[46] D. J. A. Jenkins, T. M. S. Wolever, A. L. Jenkins et al., "The glycemic index of foods tested in diabetic patients: a new basis for carbohydrate exchange favouring the use of legumes," Diabetologia, vol. 24, no. 4, pp. 257-264, 1983.

[47] A. K. Jukanti, P. M. Gaur, C. L. L. Gowda, and R. N. Chibbar, "Nutritional quality and health benefits of chickpea (Cicer arietinum L.): a review," British Journal of Nutrition, vol. 108, no. S1, pp. S11-S26, 2012. 


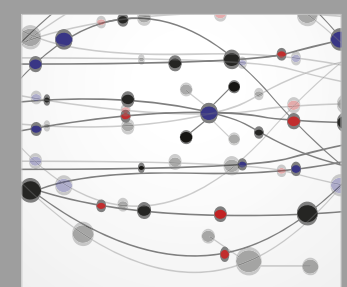

The Scientific World Journal
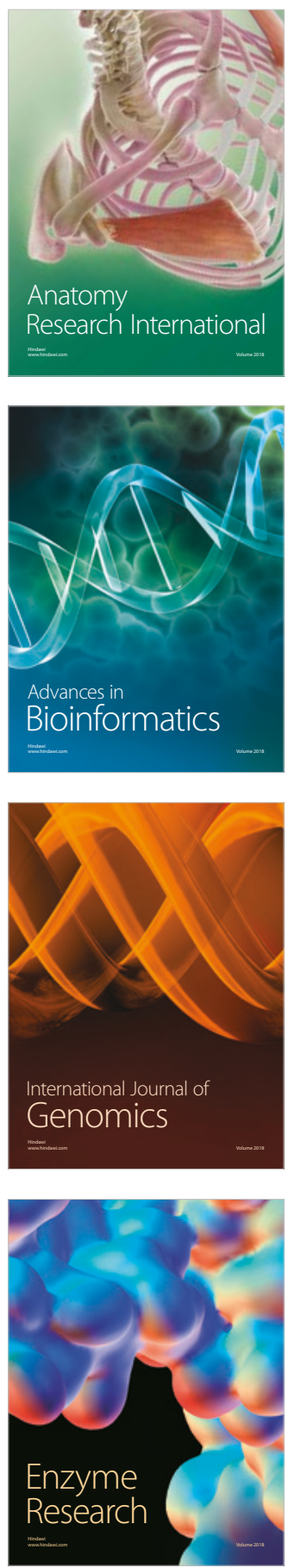
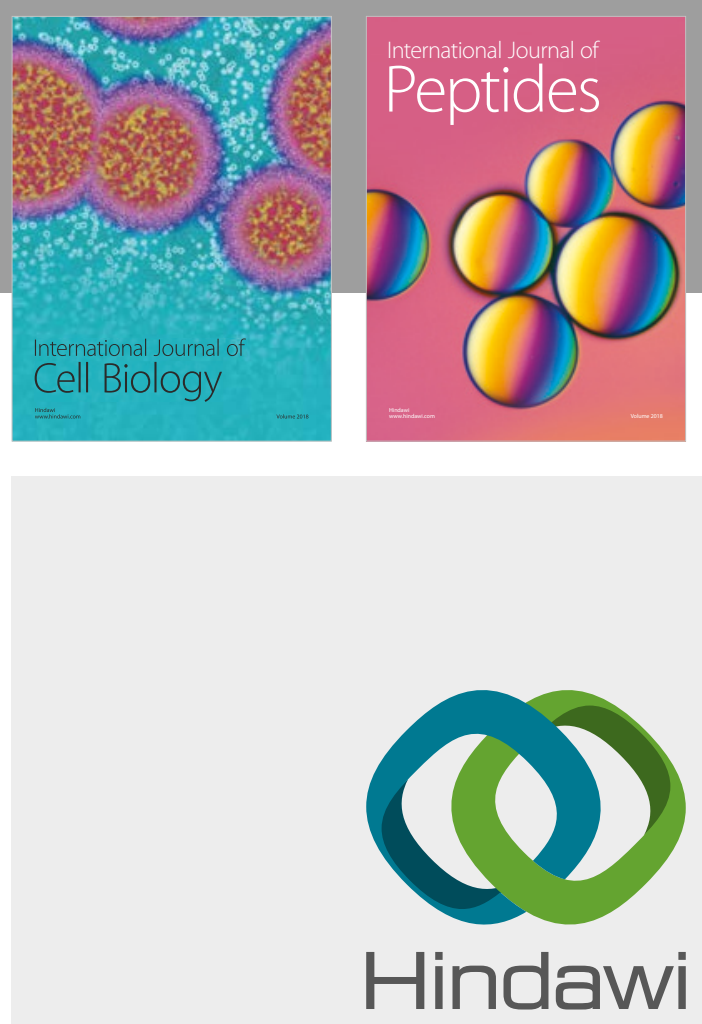

Submit your manuscripts at

www.hindawi.com
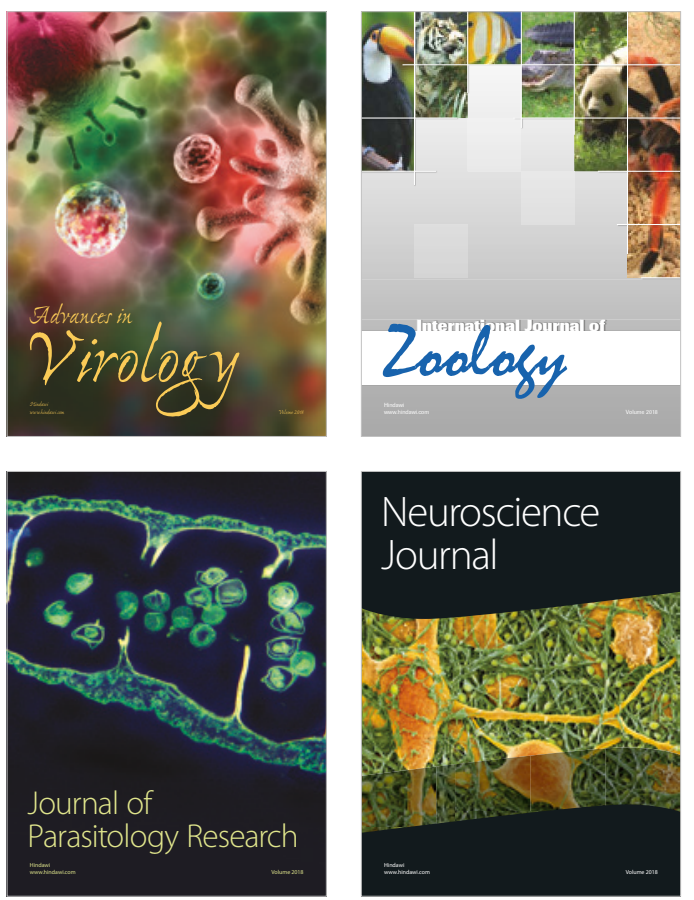
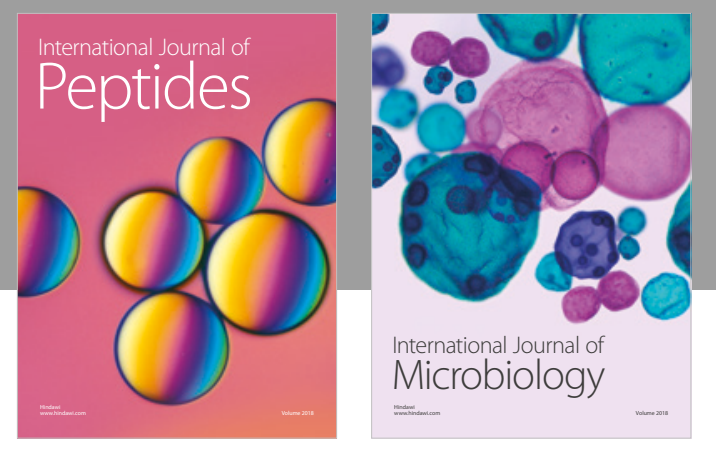

nternational Journal of Microbiology
Journal of
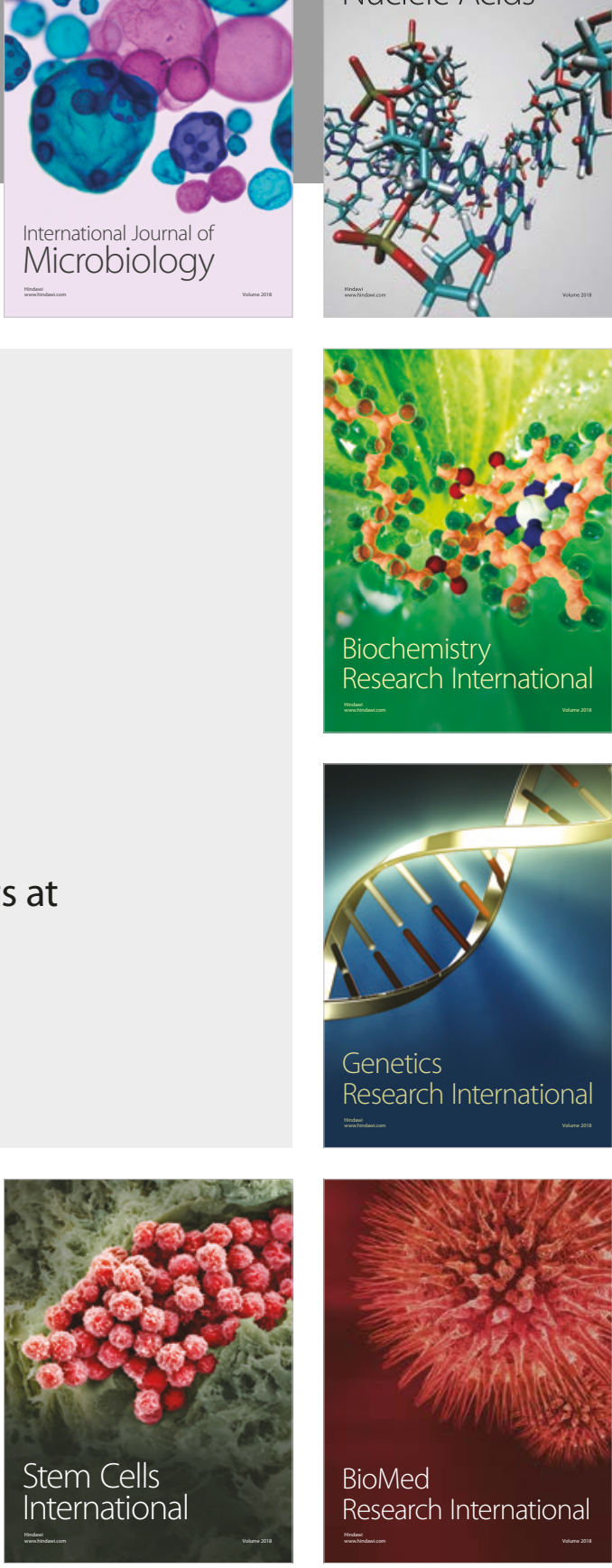
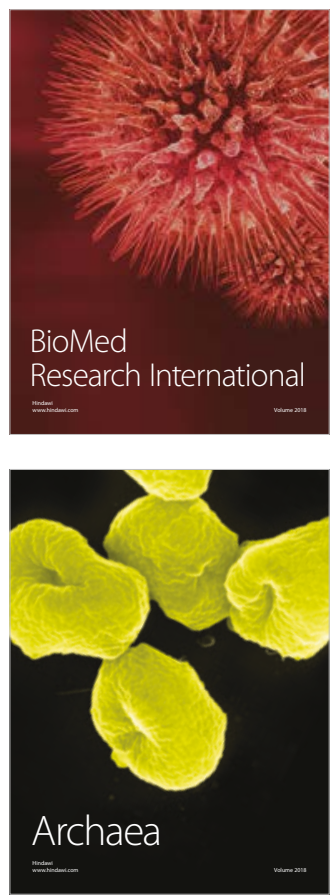